\title{
A UTILIZAÇÃO DO “LIVRO” DIDÁTICO NA SOCIEDADE DO CAPITAL"
}

\author{
Maria Lucia Paniago ${ }^{2}$
}

\begin{abstract}
RESUMO
Este artigo trata da mediação realizada pelo "livro" didático na relação pedagógica. Apesar da amplitude do debate com vasta literatura sobre o tema, a relevância da investigação ainda permanece em pauta, uma vez que ele, o "livro" didático, mantém-se soberano na práxis do professor, excluindo-o de sua tarefa na atividade educativa. Esse potente e alienante instrumento de trabalho do professor o transforma em um acessório da atividade educativa, contudo, não o livra do trabalho, mas o seu trabalho de conteúdo. Não é o professor que se utiliza das condições de trabalho, mas o oposto, são as condições de trabalho que utilizam o professor. Dessa perspectiva, temos por objetivo apontar a forma como o "livro" didático se apresenta na atividade educativa, como produto do modo de produção capitalista. Para tanto, nossa pesquisa se concentrou em três obras didáticas de ciências de duas escolas da Rede Municipal de Ensino de Campo Grande, Mato Grosso do Sul, com a intenção de demonstrar a maneira pela qual o manual didático comeniano permanece estabelecendo a simplificação e vulgarização do conhecimento produzido pela humanidade. O foco de discussão nas questões ambientais, tem relevância por serem questões determinantes do processo de produção da existência humana.

Palavras-chave: sociedade capitalista; trabalho didático; manual didático.
\end{abstract}

\section{THE USING OF DIDACTIC "BOOK" IN CAPITALIST SOCIETY}

\begin{abstract}
This article deals with the mediation carried out by the didactic "book" in the pedagogical relations. Despite the breadth of the debate with vast literature on the subject, the relevance of research still remains in question, since he, the didactic "book", remains sovereign in teaching practice, excluding him from his job in the educational activity. This powerful and alienating teacher's working tool turns him into an accessory of the teaching work, however do not frees him from the labor, but his work from contents. It is not the teacher that utilizes his labor conditions, opposite to, the labor conditions is that utilizes the teacher. From this perspective, we aim to point out how the "book" presents in educational activities, as a product of the capitalist mode of production. Therefore, our research has focused on three textbooks of science from two Municipal Schools of Campo Grande, Mato Grosso do Sul, demonstrating how the comenian didactic manual remains establishing the simplification and trivialization of the knowledge produced by mankind. The focus of discussion on environmental issues, has relevance because these are determinant for the production process of human existence.
\end{abstract}

Keywords: capitalist society; didactic labor; didactic manual. 


\section{Introdução}

Há uma extensa produção sobre o "livro" didático, até mesmo no contexto internacional $^{3}$. Isso demonstra a sua primazia no cenário da educação formal, em razão do seu potencial papel mediador no âmbito da sala de aula. Consideramos que, mesmo com a ampla literatura sobre o "livro" didático, ainda há elementos significativos para a discussão do tema aqui proposto, visto que ele permanece como o mais importante instrumento de trabalho do professor no cenário da educação escolar brasileira e, portanto, o material de maior peso para o trabalho didático, cuja produção se inscreve na lógica do capital, sob o patrocínio do Fundo Nacional de Desenvolvimento da Educação, Ministério da Educação, como mercadoria fetichizada, constitutiva do processo de reprodução ampliada do capital monopolista.

Partindo desse pressuposto, um dos objetivos da pesquisa que apresentamos neste texto, foi verificar o tratamento dado à questão ambiental pelo "livro" didático de ciências dos $5^{\circ}$ e $6^{\circ}$ anos do Ensino Fundamental (escolha aleatória). Consideramos nesta investigação o material didático selecionado por duas escolas da Rede Municipal de Ensino de Campo Grande, Mato Grosso do Sul, a partir da lista aprovada e publicada no guia do Programa Nacional do Livro Didático (BRASIL, 2015). Tomamos como foco de discussão o ensino de ciências na abordagem das questões ambientais, uma vez que na contemporaneidade tais questões são determinantes no processo de produção da existência humana. O ambiente como recorte escolhido para a discussão sobre o "livro" didático justifica-se, em razão de ser ele a maneira mais evidente para se demonstrar a reprodução destrutiva do capital.

É neste aspecto da existência humana, onde o capital tem sua mais expressiva forma de exploração da natureza e do homem como ser social, que a educação escolar pode fazer as mediações entre os conhecimentos acumulados historicamente e a formação humana integral, isto é, "[...] como acesso, por parte do indivíduo, aos bens, materiais e espirituais, necessários à sua autoconstrução como membro pleno do gênero humano [...]", o que implica na emancipação humana (TONET, 2012, p. 80). Nesse sentido, os "livros" didáticos cumprem papel importante como instrumento de trabalho do professor que, soberano em sala de aula, veicula os conhecimentos que, contraditoriamente ao seu próprio fundamento de simplificação e vulgarização dos conteúdos ${ }^{4}$ e considerando as múltiplas determinações da educação como um dos complexos sociais, "poderão" ou "não" contribuir para o pleno desenvolvimento da autoconstrução humana e sua consequente emancipação do capital.

A discussão a respeito da questão ambiental retratada no manual didático está relacionada à atual fase histórica do capitalismo, em que as condições ambientais, resultado "[...] da acumulação no quadro da dominação mundial do capital financeiro [...]", tem se agravado, dado o acelerado ritmo de degradação das condições físicas da reprodução social e, portanto, a degradação da vida (CHESNAIS; SERFATI, 2003, p. 40). Essas condições, em verdade, foram gestadas desde as origens do capitalismo e determinadas pela forma como o homem produziu os seus meios de vida, mediante o processo de transformação da natureza. Este debate reveste-se de importância no âmbito da educação escolar em razão da necessidade de apreensão da totalidade, visto que entender a existência dos homens no planeta depende do conhecimento e compreensão de como o capital determina a reprodução metabólica universal e social (MÉSZÁROS, 2005).

Segundo Foladori (2001, p. 44), a "[...] ecologia estuda a inter-relação entre as espécies e seu meio ambiente [...]", sendo o homem uma dessas espécies, a espécie humana, que transforma a natureza por meio do trabalho para atender às suas necessidades de sobrevivência e que troca o produto do seu trabalho, portanto, um ser social; partimos do 
pressuposto de que não são os fenômenos naturais, as contradições de ordem biológica ou ecológica em geral, que mediam as múltiplas condições ambientais determinantes da vida no planeta, mas as relações sociais estabelecidas no interior de uma sociedade dividida em classes (MARX, 1985a).

Até aqui, utilizamos a denominação "livro" didático que tem sido a mais usual ao referirmo-nos a esse instrumento de trabalho do professor. Entretanto, vale esclarecer que, dada a sua natureza na relação educativa, optamos pela categoria "manual didático", em razão de que esse recurso material se caracteriza por instrumentalizar e guiar o professor na forma, no conteúdo e na execução, simplificando, vulgarizando e sonegando o conhecimento construído pelo ato do trabalho, através de gerações consecutivas. É nesse processo de apropriação do conhecimento que se origina a educação e a sua ineliminável presença na formação do ser social. Sem essa mediação não seria possível a realização da construção do conhecimento.

Na concepção comeniana, o manual didático, tinha a função de facilitar o ensino, de modo que qualquer pessoa pudesse utilizá-lo para ensinar tudo a todos. Essa pessoa - o professor - não precisaria de uma formação aprofundada dos conhecimentos necessários ao exercício da função. Bastariam, a ele, os conhecimentos essenciais à utilização deste manual, tanto do professor quanto do aluno. Vale ressaltar que é a centralidade e a exclusividade que ocupa na relação educativa que confere a tal instrumento o caráter de manual e que o difere do livro didático. Dessa perspectiva, qualquer que seja o livro utilizado pelo professor pode assumir características de manual, desde que seja utilizado como fonte única de conhecimento - mesmo porque devemos considerar que seu caráter, em princípio, é este - e que seu conteúdo seja simplificado ao ponto de sonegar elementos da realidade humana que impeçam a autoconstrução do indivíduo rumo à emancipação humana.

A pesquisa apresentada neste artigo, como já afirmamos, aborda essencialmente o tratamento dado pelo manual didático às questões ambientais, no ensino de ciências, analisando como se constitui, particularmente, cada um dos manuais em estudo, além de reflexões relacionadas aos objetivos e à organização do trabalho didático. A centralidade da análise está na relação homem/natureza, trazendo para o quadro de discussão o fato de que, segundo Marx e Engels (2007), o pressuposto fundamental da existência humana é que os homens, para se manterem vivos, precisam produzir seus meios de vida e, para tal, devem transformar a natureza cotidianamente.

Assim, pautaremos a análise dos manuais didáticos de ciências investigados, na relação homem/natureza e no trabalho - atividade do homem sobre a natureza -, tendo por objetivo apontar a forma como o manual didático se apresenta na atividade educativa, como produto do modo de produção capitalista, procurando identificar o tratamento dado pelos manuais à temática ambiental, à relação estabelecida entre homem e ambiente e qual a natureza dessas relações. Para tanto, tomamos como ponto de partida a estrutura, os objetivos, a organização dos conteúdos e a abordagem ambiental veiculada por esses manuais.

Embora o levantamento dos dados empíricos tenha sido realizado no ano de 2009, o caráter da utilização do manual didático persiste, enquanto o seu fundamento responder às necessidades do capital. Analisamos os manuais didáticos de ciências de $5^{\circ}$ e $6^{\circ}$ anos do Ensino Fundamental, como evidência da maneira pela qual o manual didático comeniano permanece estabelecendo a simplificação e a vulgarização do conhecimento produzido pela humanidade. Para essa análise três aspectos foram observados: 1) o tratamento dado às questões ambientais; 2) as orientações aos professores sobre o modo de utilização desse instrumento de trabalho; 3) o nível de autonomia do professor para buscar em outras fontes clássicas e/ou científicas os conhecimentos e formas para o desenvolvimento do trabalho 
didático.

\section{O manual didático comeniano}

Os elementos apresentados neste item, como veremos, indicam que qualquer semelhança não é mera coincidência. As formulações de Jan Amos Comenius ${ }^{5}$ permanecem ainda muito presentes na estrutura de ensino da sociedade capitalista. Todo o fundamento do modo de produção do sistema do capital está nas entranhas da educação moderna. São os pressupostos comenianos que se mantêm como fundamento da educação contemporânea, com o manual didático ditando as regras da práxis ${ }^{6}$ docente.

O manual didático concebido por Jan Amos Comenius, em Didática magna (16211657), como ferramenta dominante na prática docente, teve o propósito de ensinar tudo a todos de modo certo, fácil, sólido, com economia de tempo e para facilitar a execução do método. Assim, insere-se na pedagogia comeniana como um instrumento para o professor, na organização do trabalho didático, já que nele estariam contidos todos os conteúdos necessários às aulas e, dessa forma, dispensando o professor do conhecimento erudito (COMENIUS, 2006). Tal forma de organizar o trabalho didático veio se materializar a partir do século XIX, em razão do desenvolvimento das forças produtivas, propícias à instauração da escola moderna. Assim, educação, como uma das dimensões da sociedade, também se transformava pelas mãos de vários outros pensadores como o italiano Tommaso Campanella (1568-1639) e os alemães Wolfgang Ratke (1571-1635), Johann Heinrich Alsted (15881638) e Johannes Valentinus Andreae (1586-1654), contemporâneos de Comenius dos quais recebeu grande influência (CAMBI, 1999) ${ }^{7}$. Vale ressaltar que o avanço nas transformações sociais do modo de produção feudal para o modo de produção capitalista, sujeitaram também a educação, às simplificações que se fizeram necessárias ao desenvolvimento do capital.

Para Comenius (2006), a organização da escola deveria observar o tempo de trabalho empregado na realização das atividades, para que não se tornassem cansativas ou aborrecidas. Referindo-se a distribuição do tempo, considerava a divisão das matérias em horas, dias, meses e anos, em um processo gradual e proporcional às capacidades e faixa etária dos alunos. No sentido de ensinar e aprender com certeza de atingir o objetivo, julgava o educador ser

[...] um absurdo que os mestres não distribuam os estudos, para si e para os alunos, de tal modo que uns não se sucedam naturalmente aos outros, mas que cada matéria seja completada em dado limite de tempo. Se não se estabelecerem muito bem os fins, os meios para atingir esses fins e a ordem dos meios, será fácil esquecer ou inverter alguma coisa, e todo o estudo de algum modo será prejudicado. (COMENIUS, 2006, p. 160).

Como se vê, a arte de ensinar tornava-se uma atividade rigorosamente planejada, todo o trabalho didático articulado em tempo determinado e conteúdos sistematicamente organizados, numa progressão de estudos baseados nos precedentes que os consolidariam: "[...] tudo o que precede deve servir de fundamento para o que segue, tudo deverá ser apresentado o mais solidamente possível." (COMENIUS, 2006, p. 194). Este método compreendia o ensino somente das coisas úteis de uso imediato, por meio da experiência direta, esclarecendo suas finalidades e com um único e imutável método, para todas as ciências, todas as artes e todas as línguas, o que denota o caráter utilitarista e mecânico de sua proposta: "[...] instruir bem os jovens não significa atulhar suas mentes com um amontoado de palavras, frases, sentenças, opiniões extraídas dos autores, mas, pelo 
contrário, desenvolver o entendimento das coisas [...]" (COMENIUS, 2006, p. 189).

Organizada dessa forma a instrução comeniana e pautada na divisão social do trabalho e no modelo manufatureiro de organização do trabalho, seria necessário um instrumento que organizasse todo o conteúdo de forma a ensinar apenas as coisas úteis de uso imediato, uma vez que todo o conhecimento humano necessário à formação do homem para tornar-se homem estava disperso em variadas fontes (antologias e obras clássicas).

A solução para esta questão o próprio Comenius (2006, p. 95) nos dá ao dizer

[...] que nas escolas é preciso ensinar tudo a todos. Isso não quer dizer que queiramos para todos um conhecimento (exato e profundo) de todas as ciências e artes: isso não seria útil em si mesmo nem possível a ninguém, tendo em vista a brevidade da vida [...]".

Com o intuito de atender a essa proposição, foi instituído um novo instrumento - o manual didático - que poderia conter todos os conteúdos considerados, por ele, como coisas úteis e de uso imediato, evitando a multiplicidade de objetos que distraem os nossos sentidos. "Faze isto, e basta! [...] quando menos os outros livros ocuparem os olhos tanto mais os didáticos ocuparão os espíritos [...]" (COMENIUS, 2006, p. 216).

Para proceder à expansão do ensino, o autor acreditava ser necessário aos alunos apenas as coisas úteis, dispensando dessa forma todo o conhecimento erudito acumulado historicamente. Entendia ele que seria inútil aprender muitas coisas, "[...] que não é sábio quem conhece muitas coisas, mas quem conhece coisas úteis, [que] poderemos facilitar as tarefas escolares se soubermos fazer um resumo das matérias [...]" (COMENIUS, 2006, p. 337, grifo nosso).

O manual didático, vale registrar, na perspectiva comeniana, adquiriu, então, um caráter excludente em sala de aula, eliminando qualquer possibilidade de acesso ao conhecimento culturalmente significativo, como se pode observar no excerto: "Enquanto os jovens estiverem nessa escola esses livros deverão, infalivelmente, servir de orientação até a meta desejada, sem necessidade de nenhum outro [...]" (COMENIUS, 2006, p. 337, grifo nosso).

Cabe ressaltar que, para a efetivação dessa didática, também o professor seria instrumentalizado com o seu livro de informações, onde estariam preparadas, antecipadamente, por outrem, as aulas correspondentes às lições dispostas no manual do aluno, com maior segurança e menos erros:

[...] ninguém deverá tirar apenas da própria cabeça o que vai ensinar e como ensinar, mas principalmente instilar e infundir nos jovens uma instrução já preparada, com meios que encontrará pronto, ao seu alcance. [...] por que não poderá o mestre ensinar qualquer coisa, se já encontra pronta, como se impressas numa partitura, as coisas que deverão ser ensinadas e o modo de fazê-las? (COMENIUS, 2006, p. 363).

É no período manufatureiro que o autor elabora a sua proposição de ensino nos moldes do modo de produção regido pelo capital que se consolidava. O educador morávio propõe, nesse momento, para a educação formal o potente e alienante instrumento do professor - o manual didático, que alavancou a divisão do trabalho na escola, em concepção e execução. Parafraseando Marx (1985b), e por analogia, podemos dizer que o manual didático não livra o professor do trabalho, mas seu trabalho de conteúdo. Não é o professor que se utiliza das condições de trabalho, mas o oposto, são as condições de trabalho que utilizam o professor. Assim, o professor da escola comeniana não se reconhece nas escolhas e na atividade de ensino, pois a função social do seu trabalho no capitalismo tem por 
pressuposto incondicional a produção da mercadoria educação. Na sociedade do capital, trabalhador, educação, arte, esporte, lazer, etc., tudo se resume à mercadoria.

As formulações de Comenius (2006) podem ser facilmente identificadas no processo educativo levado a cabo na escola contemporânea. Como o que determina a sociedade é o avanço das forças produtivas, com a educação como uma de suas mediações não poderia ser diferente. Evidências das proposições do educador morávio que permanecem, mesmo com o desenvolvimento da tecnologia, podem ser observadas no trabalho cada vez mais simplificado do professor; no uso do manual didático, mesmo que apresentado de diferentes formas, com o suporte da informática, por exemplo, na Educação a Distância; na vulgarização e simplificação do conhecimento veiculado pelos instrumentos tecnológicos. Vale ressaltar que nem a pura e simples substituição de tradicionais instrumentos de trabalho por outros de tecnologia avançada, nem a eliminação do manual didático da escola, podem garantir a superação da atual organização do trabalho didático. Isto é, não é a conformação do instrumento que determina as transformações, mas a forma como são utilizados e estruturados que permitem o surgimento de novas relações educativas.

\section{Caracterização do manual didático na contemporaneidade}

Reafirmando, o meio de produção da educação escolar, para a consecução da proposta comeniana foi o manual didático como instrumento de trabalho do professor, que ao liberá-lo do esforço intelectual, torna-o apenas um acessório do processo de ensino. Esses mesmos elementos permeiam ainda hoje $\overline{\text { o }}$ cenário objetivo da educação escolar. Ao longo dos séculos algumas mudanças ocorreram, mas não tão significativas ao ponto de fugir da essência alienante da educação formal, escolar sob a determinação do capital. Ao contrário, isso demonstra a tendência à prevalência da produção e intensificação das alienações, das misérias materiais e culturais. Assim, neste item, procuramos demonstrar como os fundamentos do manual didático presentes na proposta de Comenius (2006), são preservados no atualizado instrumento de trabalho do professor.

Destacamos três dos manuais didáticos adotadas pelas escolas participantes da pesquisa: 1) Projeto Pitanguá: Ciências (2005) ( $1^{\mathrm{a}}$ a $4^{\mathrm{a}}$ séries), escolhido pelas escolas A e $\mathrm{B}^{8}$; 2) Projeto Araribá: Ciências $(2006)\left(5^{\mathrm{a}}\right.$ a $8^{\mathrm{a}}$ séries), adotado pela escola A - ambos os manuais organizados e publicados pela Editora Moderna; e 3) Ciências: meio ambiente (2006) ( $5^{\mathrm{a}}$ a $8^{\mathrm{a}}$ séries) selecionado pela escola $\mathrm{B}$, de autoria de Carlos Barros e Wilson Roberto Paulino, publicado pela Editora Ática.

É importante frisar que para o ano de 2009 , os manuais didáticos adotados para os $5^{\circ}$ e $6^{\circ}$ anos do Ensino Fundamental foram os da $4^{\mathrm{a}}$ e $5^{\mathrm{a}}$ séries do ano anterior, respectivamente, tendo em vista a implantação do Ensino Fundamental de nove anos, regulamentada pela Lei n. 11.274, de 6 de fevereiro de 2006, e a inexistência de material didático adequado a nova estrutura de ensino. Essa reformulação ocorreu, conforme o documento oficial intitulado Ensino fundamental de nove anos: orientações para a inclusão da criança de seis anos de idade (2007), em função da

[...] inclusão de um número maior de crianças no sistema educacional brasileiro, especialmente aquelas pertencentes aos setores populares uma vez que as crianças de seis anos de idade das classes médias e altas já se encontram, majoritariamente, incorporadas ao sistema de ensino - na préescola ou na primeira série do ensino fundamental. (BRASIL, 2007, p. 5). ${ }^{9}$

Ressaltamos que os três manuais didáticos, ora analisados, têm em comum quatro 
aspectos: 1) o caráter descritivo do conteúdo e as inúmeras imagens e ilustrações de um rico colorido, as quais ocupam, aproximadamente, $50 \%$ de suas páginas; 2) a forma como os manuais didáticos se apresentam aos alunos; 3) as páginas iniciais que trazem algumas informações sobre a organização da obra e um sumário com a distribuição dos conteúdos nas respectivas unidades; 4) um manual para o aluno e outro para o professor trazendo ao final da obra o encarte denominado Manual do professor ou Suplemento do professor, onde apresenta as instruções para a sua utilização.

Como já apontamos, a proposta comeniana para o manual didático determina que todo o conteúdo deve se limitar às coisas úteis e de uso imediato e estar condensado em um único material, preparado antecipadamente por outros que não o professor. Constatamos, então, que essa prescrição permanece no que concerne a autoria dos manuais investigados, sendo dois deles - Projeto Pitanguá: Ciências (2005) e Projeto Araribá: Ciências (2006) elaborados por um grupo de profissionais que, segundo a editora, o concebem e desenvolvem coletivamente e, posteriormente é por ela produzido. A ficha técnica desses manuais trazem informações sobre os responsáveis pelo trabalho, que constam: da equipe de "elaboração dos originais" - quatro graduados em Biologia e uma pedagoga -, do "coordenador editorial", da "editora de texto" e demais técnicos da parte de produção gráfica, revisão e arte.

Já o manual didático o Ciências: o meio ambiente (2006) vem assinado por dois autores: Carlos Barros (licenciado em História Natural) e Wilson Roberto Paulino (Engenheiro-agrônomo e licenciado em Biologia). Frisamos que a editora registra também outros profissionais envolvidos na realização da obra, tais como a responsável pela redação, edição de texto e coordenação, além da equipe de consultoria didática composta por professores atuantes na Universidade de São Paulo. Cabe observar que a forma como os três manuais são elaborados, evidenciam a divisão do trabalho no processo educativo, caracterizando a ação parcelar na educação.

Esses procedimentos vêm confirmar as pesquisas de Gatti Junior (2004, 2005) e Munakata (1997) sobre a relação editora/autores, em que constatam que até a década de 1960 os manuais didáticos eram elaborados quase exclusivamente pelos autores e seus editores. A partir dessa década, os autores perdem a autonomia sobre seus escritos, ficando as decisões relativas à estrutura e ao conteúdo das obras sob a responsabilidade das editoras, embora em alguns casos lhes seja permitido "acompanhar" todo o processo de produção.

É importante destacar a concepção que permeia toda a obra sobre o tema ambiente tratado por Barros e Paulino (2006, p. 11, grifo dos autores), em Ciências: o meio ambiente: logo na primeira unidade sobre "Os seres vivos e o ambiente", na seção "Desafios do presente", os autores explicitam o seu entendimento a respeito da ecologia como sendo "[...] a ciência que estuda as 'casas naturais', isto é, os diversos ambientes da natureza, incluindo as relações dos seres vivos entre si e com o ambiente [...]"; no parágrafo seguinte, afirmam que o "ambiente" "[...] pode ser entendido como o conjunto formado por todos os seres vivos que nele vivem mais os fatores não-vivos ali existentes, como água e temperatura [...]"; ainda na mesma seção afirmam ser "[...] a ecologia [...] uma ciência que contribui para uma relação mais harmoniosa e produtiva dos seres humanos com a natureza [...]" (grifo nosso).

Dessas afirmações, podemos observar, em primeiro lugar, que as duas definições são coincidentes entre si, já que, para os autores, tanto ecologia como ambiente dizem respeito à mesma questão: relação homem/natureza. Tais definições omitem o que de mais importante poderia ser abordado, ou seja, como e por quê meio essa relação se realiza. Da forma como está colocada, a concepção de ecologia/ambiente não traz para o campo de discussão o fundamento da relação homem/natureza e a relação dos homens entre si, que se dá pelo trabalho. É a partir do trabalho, meio pelo qual os homens constroem materialmente a sociedade e lançam as bases para a sua própria construção, que os problemas ambientais 
apontados pelo manual podem ser desvendados e compreendidos.

Em segundo lugar, não há possibilidade de uma relação harmoniosa entre homem e natureza no modo destrutivo de produção capitalista. Para que o capital se reproduza indefinidamente, é necessário romper com todas as barreiras e contradições que o impedem de reproduzir-se, ou seja, "[...] uma total integração benéfica e racionalização cooperativa da produção material e intelectual numa escala global." (MÉSZÁROS, 2006, p. 86). A realização do capital exige a exploração sempre crescente, portanto, destrutiva dos recursos naturais como meio de produção para a autoexpansão do valor-de-troca e isso não pode ser feito de maneira harmoniosa, pois não se produz para atender às reais necessidades humanas, mas para atender às necessidades de ampliação ilimitada do capital.

Os manuais didáticos Ciências: o meio ambiente (2006), Projeto Pitanguá: Ciências (2005) e Projeto Araribá: Ciências (2006) estruturam-se em unidades que têm o propósito de uma abordagem ecológica, enfocando com especial atenção o desequilíbrio ambiental. Nos demais capítulos as questões ambientais articulam-se de forma diluída nos conteúdos ali apresentados ou por meio de pequenos textos complementares. Os manuais didáticos apresentam, como conteúdo de suas unidades, informações genéricas e fragmentadas, entrecortadas por boxes com pequenos textos adicionais, além de sugestões de endereços eletrônicos para consulta. Ao final, completam essa estrutura um glossário para auxiliar o aluno com palavras ou expressões novas.

Nos encartes desses manuais dedicados aos professores, inserem-se orientações sobre o trabalho com mapas conceituais sem anunciar sua respectiva concepção, apresentando apenas as explicações de como utilizá-lo. Nesse formato, todo o conhecimento, além de hierarquizado, se reduz a conceitos isolados sem a necessária articulação recíproca entre eles. Esse tratamento dado ao conhecimento e a prescrição precisa do encaminhamento das aulas, descompromete o professor de sua autonomia para definir o que considera conhecimento significativo, colocando-o em uma camisa de força e impelindo-o a apresentar um conteúdo ideologicamente simplificado, vulgarizado e sonegado, personificado pelos interesses do capital.

Os manuais do professor ainda apresentam orientações sobre a avaliação que tem como pressuposto a expectativa dos resultados, expondo os progressos desejáveis. Nesse item os autores fazem sugestões de avaliação convencionais como prova escrita, prova oral, pesquisa realizada em casa, trabalhos realizados em classe e autoavaliação, acompanhadas de orientações sobre o seu procedimento.

É a partir da burocratização hierarquizada do ensino que os conteúdos curriculares são ditados à escola. O professor, como trabalhador do complexo da educação, é excluído do planejamento e controle de seu próprio trabalho. A organização e o desenvolvimento do trabalho didático se realizam de forma alheia e exterior a ele. Isso não quer dizer que do ponto de vista das características humanas, sua subjetividade não esteja presente. Porém, ele perde o controle e o domínio da totalidade do processo global de sua práxis e, portanto, não realiza as objetivações materiais e ideais enquanto ser social que é.

Isto faz com que as "forças espirituais" do trabalho, a sua subjetividade, sejam atrofiadas no processo de trabalho alienado. Dessa forma se revela a natureza do modo de produção capitalista, que transforma o "[...] trabalhador em acessório consciente de uma máquina parcelar [...]", ou seja, o "livro" didático e a tecnologia digital (MARX, 1985b, p. 87). Estabelecida a caracterização dos três manuais didáticos destacaremos, a seguir, alguns aspectos que consideramos relevantes para análise deste estudo. Esses aspectos referem-se aos objetivos, ao conteúdo e ao trabalho didático. 


\section{Reflexões a respeito dos objetivos e da abordagem dos manuais didáticos}

$\mathrm{Na}$ análise dos objetivos que sustentam os manuais didáticos constatamos que os mesmos não são dados a conhecer por pais e alunos, sendo apresentados apenas no Manual do professor. Isso implica no desconhecimento, por parte dos interessados, sobre a natureza do conhecimento a ser transmitido na escola, considerando o processo de desenvolvimento humano real a partir das condições de existência humana e do modo como esta se produz e reproduz. Mas isso não se dá apenas com pais e alunos. Para o professor, embora tenha acesso a tais objetivos, não significa participação na definição dos mesmos, uma vez que eles já vêm previamente determinados no manual didático.

Basta observar em Ciências: o meio ambiente, quando Barros e Paulino (2006, p. 3) apontam o conhecimento científico como a ampliação de "[...] nossa capacidade de compreender e atuar no mundo em que vivemos [...]". Percebe-se nessas afirmações o caráter cientificista da concepção que permeia a obra. O que nos leva a crer que, para os autores, o "conhecimento científico" está relacionado ao conhecimento positivo que se esgota em seu próprio interior. Tal entendimento da ciência se confirma quando dizem:

Graças à abrangência e à natureza dos objetos de estudo das ciências, o trabalho escolar pode ser efetivado de forma bastante dinâmica, despertando o interesse do estudante para a observação de fenômenos da natureza e dos mais diversos produtos tecnológicos, tanto os que estão próximos como os mais distantes no espaço e no tempo. (BARROS; PAULINO, 2006, p. 3, grifo nosso).

Fazendo parte do "conjunto de objetivos para o ensino de ciências", estabelecem que os alunos devem adquirir "[...] um conjunto de conceitos, procedimentos e atitudes que operem como instrumento para a interpretação do mundo científico e tecnológico, capacitando-o nas escolhas que fará como indivíduo e como cidadão." (BARROS; PAULINO, 2006, p. 3, grifo nosso). Aqui, como em outros momentos no texto, evidenciase a concepção individualista de homem, que perpassa os objetivos educacionais declarados, característica do modo de produção capitalista. Nesse sentido, "escolher o que fará como indivíduo" significa, na sociedade burguesa, o rompimento com a conexão indivíduosociedade e a relação entre as pessoas se torna uma relação entre adversários, uma vez que

[...] A vida social passa a ser predominantemente marcada pela propriedade privada, e a razão da existência pessoal deixa de ser a articulação com a vida coletiva, para ser o mero enriquecimento privado. O dinheiro passa a ser a medida e o critério de avaliação de todos os aspectos da vida humana, inclusive os mais íntimos e pessoais [...]. (LESSA; TONET, 2008, p. 81).

Assim como o caráter individualista verificado nas propostas, de maneira mais sutil, o conceito cidadania também se faz presente no Manual do professor ao explicitar os objetivos dos manuais didático. Exemplo disto é o que afirmam Barros e Paulino (2006, p. 3, grifo nosso), em Ciências: o meio ambiente:

Ao desenvolver e possibilitar ao aluno o exercício da solidariedade, da cooperação, do respeito às normas e à opinião dos colegas e às diferenças culturais, a escola promove oportunidades para o exercício da cidadania de forma consciente, contribuindo para a formação de uma postura participativa de indivíduos ciosos de seus direitos e deveres. 
Esse conceito, na perspectiva liberal, é tomado como sinônimo de liberdade, como a expressão mais elevada de liberdade humana, todavia uma liberdade jurídico-política. Tal liberdade se inscreve em uma sociedade de classes, onde leis regulam os "direitos e deveres" do "cidadão", mas não explicita a quem cabem tais direitos e deveres, respectivamente. Como é sabido, em uma relação entre dominantes e dominados os direitos são privilégios dos dominantes e os deveres são deveres dos dominados. Assim, para romper com esse pressuposto é necessário compreender o que é ser cidadão, a partir da totalidade social na perspectiva do capital.

Para Marx e Engels (1990, p. 87), cidadania é uma forma de opressão que pertence ao campo da política, e política propriamente dita é para ele "[...] o poder organizado de uma classe para opressão de outra." Cidadania então significa emancipação política e não emancipação humana, considerando-se esta última como uma forma de sociabilidade em que os homens sejam verdadeiramente livres do capital, alicerçada em sua mais completa superação. Propor, portanto, a formação para a cidadania é, antes de tudo, formar para que os indivíduos se conformem com a sociedade capitalista e, no máximo, para que busquem melhorá-la, no sentido idealista, reformando o irreformável. Por outro lado, formar para a emancipação humana é conectar a atividade educativa com todas as mediações necessárias à superação radical do capital. E isto em absoluto está posto em questão para os autores.

A análise dos objetivos específicos dos manuais didáticos em questão, que, segundo seus autores, são adaptados dos Parâmetros Curriculares Nacionais: Ciências Naturais (1998), que trazem questões importantes a serem discutidas. Antes de tudo, salientamos que, no conjunto, os objetivos ${ }^{10}$ apresentam uma visão reducionista e enganosa das questões ambientais. Contudo, segundo Foladori (2001), os aspectos sobre os limites físicos do planeta merecem atenção em virtude de que, não é discussão encerrada. De acordo com os estudos do autor, o que deve ser considerado importante é "[...] se o ritmo de utilização desses materiais implica um esgotamento previsível futuro [...]", visto que, na falta ou escassez de um produto, historicamente as sociedades têm demonstrado a "possibilidade de substituição" dos recursos naturais (p. 18, grifo do autor). E essa questão não tem espaço nesse manual.

Se considerarmos os princípios determinados para o manual didático comeniano, veremos que os atuais manuais correspondem de forma inequívoca às características apontadas pelo seu criador. Retomando Comenius (2006, p. 95): "Isso não quer dizer que queiramos para todos um conhecimento (exato e profundo) [...]". Os objetivos declarados nos manuais são a clara evidência desta afirmação, pois são esvaziados de sentido, excluindo do debate as raízes das causas socioeconômicas determinantes da destruição ambiental. Assim, é possível afirmar a superficialidade do manual didático que sonega aos alunos o conhecimento que pode, em determinada medida, contribuir para a autoconstrução dos indivíduos.

Em Ciências: o meio ambiente, Barros e Paulino (2006, p. 4, grifo nosso) indicam que a obra deve "[...] auxiliar o educador a formar, em seus alunos, uma mentalidade crítica e sintonizada com o tempo presente, embasada em conteúdos conceituais pertinentes à faixa etária [...]", uma vez que o manual didático da $5^{\text {a }}$ série é "destinado" ao estudo do meio ambiente, justificando, assim, o título da obra. Ressaltamos aqui que, da mesma forma que o manual em referência, a proposta de ensino das outras obras em estudo asseveram que os manuais didáticos cumprem o papel de auxiliar na formação da "mentalidade crítica" do aluno. Entretanto, a julgar pelo conteúdo oferecido nesses manuais, revela-se a contradição entre o que se propõe e o que se realiza.

Analisemos primeiramente a expressão "mentalidade crítica". De acordo com o Dicionário Houaiss de língua portuguesa, mentalidade é um "[...] conjunto de crenças e 
hábitos do espírito que informam e comandam o pensamento de uma coletividade, comuns a cada membro dessa coletividade [...]" (HOUAISS; VILLAR, 2009). Se assim o é, como é possível haver crítica sobre questões de crença e costumes? Se estamos tratando de conhecimento, estamos tratando do processo real da existência humana e não de crenças que permeiam o senso comum. Estamos tratando de enfrentar problemas cotidianamente e de buscar soluções alternativas para eles, porque é da natureza essencial do homem dar respostas. E principalmente, porque ao decidir qual a melhor alternativa de resposta, é uma decisão efetivamente consciente, é uma decisão humana e não uma ideia caída do céu como diria Marx e Engels (2007). São decisões terrenas, concretas e não imaginação ou ilusão do pensamento. Entender o ensino como "formação da mentalidade crítica" é obscurecer o conhecimento - uma produção exclusiva e efetivamente humana - e a responsabilidade sobre ele. $\mathrm{O}$ conhecimento não pode ser àquilo que se pensa ou se idealiza da realidade, mas aquilo que a realidade é. O que garante o conhecimento da realidade é "[...] a existência de uma lógica própria do objeto, que impede que o sujeito do conhecimento lhe atribua uma lógica proveniente da sua própria cabeça." (TONET, 2011, p. 137).

Boa parte dos teóricos da educação enfatiza a formação do cidadão crítico no sentido da participação e luta, ciosos de seus direitos. Eles afirmam a formação de trabalhadores críticos como sinônimo de liberdade. Contraditoriamente, esse trabalhador crítico não é, de fato, livre, uma vez que mesmo crítico ele continua a ser explorado. Para Tonet (2007, p. 4),

[...] Ser crítico, no sentido radical do termo, é ser revolucionário. Esse é o sentido efetivamente possível de ser crítico no sentido marxiano do termo: ser revolucionário, não é ser cidadão. [...] formar cidadãos é formar pessoas que não estão aceitando os desmazelos do capitalismo, com toda essa violência e desigualdade social extremadas, mas querem lutar por uma sociedade "mais justa", "mais humana", "mais igualitária". Ora, mais justa, mais humana, mais igualitária tem na Suíça, tem na Suécia quando se compara com o Brasil ou com o Burundi. O problema não é mais justa, livre e igualitária e esta só é possível para além do capitalismo.

Tais considerações nos permitem perceber como os conteúdos contidos nos manuais didáticos são abordados por meio de itens desconectos, estratificados e, ainda mais, sem considerar as necessidades ou condições históricas para a construção dos conhecimentos em pauta. Como se "[...] a ciência pura, [...] se desenvolvesse à margem da história global dos homens e se mantivesse imune às contingências dessa história global [...]", na afirmação Konder (2009, p. 100, grifo do autor). Embora haja uma tentativa de dar um tratamento histórico ao conhecimento, nos manuais didáticos Ciências: o meio ambiente (2006) e Projeto Pitanguá: Ciências (2005) - um dos poucos momentos em que essa abordagem se insere nas obras - isso se concretiza de forma secundária, fragmentada e factual, como se a história dos homens fosse feita em pedaços que se sobrepõem, sem considerar o movimento histórico concreto. Isto é, aquele em que os homens são artífices de seu próprio destino, porque têm a capacidade de transformar a natureza pelo trabalho e ao fazê-lo constroem materialmente a sociedade dia a dia, construindo-se, também, como indivíduos (MARX, 1985a). Esse é o fundamento do ser social, pois “[...] essa articulada transformação da natureza e dos indivíduos permite a constante construção de novas situações históricas, de novas relações sociais, de novos conhecimentos e habilidades, num processo de acumulação constante e (contraditório).” (LESSA; TONET, 2008, p. 26).

Ainda sobre o tratamento dado aos conteúdos, em Ciências: o meio ambiente, Barros e Paulino (2006, p. 42-43) trazem à discussão o "desequilíbrio ecológico" associado aos vários tipos de relações estabelecidas em um determinado ecossistema, onde apresenta um 
texto para exemplificar o predatismo ${ }^{11}$; relatam um fato ocorrido com os veados no Arizona (EUA), quando “[...] com a intenção de aumentar essa população - pois a carne desse animal era apreciada como alimento pelas pessoas -, iniciou-se uma caçada impiedosa aos pumas, coiotes e lobos [...]" predadores do veado, tendo como resultado a destruição da vegetação, causando sua morte por falta de alimento, o que impediu o aumento da quantidade de veados como o desejado. A abordagem do tema, além de revelar uma visão ideológica de "presa" e "predador", vencedor e vencido, conceitos construídos pela espécie humana com base em suas relações sociais, ainda trata sobre o desequilíbrio ecológico de maneira parcial, pois, como afirma Foladori (2001, p. 44-45), para alguns

Os problemas ambientais se convertem em relações contraditórias: a que se dá entre congêneres. O conceito de problemas ambientais como espécies versus meio ambiente reflete uma visão parcial. Ao ser humano "não interessam" os problemas internos de cada espécie e muito menos o destino dos mais frágeis, mas tão-somente os daqueles que triunfam. Por isso falase de equilíbrio quando a espécie está adaptada, ainda que a maioria dos indivíduos dessa espécie morra ou não chegue a reproduzir-se. Ao contrário, onde uma espécie se reproduz atentando contra os recursos ou possibilidades de sobrevivência de outras, fala-se de desequilíbrio. Prioriza-se, assim, o equilíbrio da espécie, em detrimento do desequilíbrio individual da maioria. Trata-se, sem dúvida, da visão dos vencedores. [...] em termos de sociedade humana e da atual crise ambiental, essa é uma visão dos vencedores [que] assume implicações políticas significativas.

Essas implicações dizem respeito ao caráter da espécie humana, que, diferentemente de outras espécies de seres vivos, excetuando-se os elementos genéticos similares, constituise em um ser que transforma a natureza pelo trabalho, fator determinante de sua existência, "[...] eterna necessidade natural de mediação do metabolismo entre homem e natureza e, portanto, da vida humana [...]" (MARX, 1985a, p. 172). Ao realizá-lo, os homens trocam entre si o produto do seu trabalho e nesse processo desenvolvem formas históricas de relações sociais, que culminaram em uma sociedade dividida em classes e quando uma das classes acumula riquezas em detrimento da outra, movimento esse regido pelo capital, que antes de tudo é uma relação social.

Na unidade V, do manual didático Ciências: o meio ambiente (2006), que aborda os Desequilíbrios Ambientais, o texto de abertura é extremamente esclarecedor quanto à generalização feita com as responsabilidades que "temos" com o planeta:

A Terra fornece-nos o gás oxigênio, a água, os alimentos e os materiais de que necessitamos para nossa sobrevivência, entre outras condições. / Para continuar desfrutando de todos esses bens precisamos recuperar, conservar e preservar a biosfera e explorar os recursos ambientais sem comprometer a qualidade de vida das gerações futuras. / Nesta unidade, estudaremos as principais formas de desequilíbrios ambientais que a interferência humana vem provocando. (BARROS; PAULINO, 2006, p. 215).

O mesmo pode ser notado na unidade 3 do manual didático Projeto Araribá: Ciências (2006), quando aborda os temas Desgaste do solo e Manejo adequado do solo, acrescido de uma receita para reduzir a poluição do solo:

A erosão e a contaminação dos solos são causadas por fatores ambientais e por influência humana. Entre os fatores ambientais que provocam o desgaste do solo estão ventos, chuvas, variações de temperatura, neve e 
insolação. Esses fatores, se associados à retirada da cobertura vegetal para práticas agrícolas e pecuárias, industrialização e urbanização, podem fazer com que os solos sejam degradados ou tornem-se poluídos. (EDITORA MODERNA, 2006, p. 68).

Para esses manuais, os desequilíbrios ambientais são computados à interferência "humana", o que pode significar o ser humano generalizado e não uma relação capital e trabalho, cujo resultado é o impulso capitalista para a expansão da produção sem ligação com a "[...] necessidade humana como tal, mas somente ao imperativo abstrato da 'realização' do capital.” (MÉSZÁROS, 1989, p. 56, grifo do autor).

Galeano (2009, grifo do autor) confere clareza à discussão:

A saúde do mundo está um asco. 'Somos todos responsáveis', clamam as vozes de alarme universal, e esta generalização absolve: se todos nós somos responsáveis, ninguém o é. Tais como coelhos, reproduzem-se os novos tecnocratas do meio ambiente. É a taxa de natalidade mais alta do mundo: os peritos geram peritos e mais peritos, que se ocupam em envolver o tema no papel celofane da ambiguidade. / Eles fabricam a brumosa linguagem das exortações ao 'sacrifício de todos' nas declarações dos governos e nos solenes acordos internacionais que ninguém cumpre. Estas cataratas de palavras - inundação que ameaçam converter-se numa catástrofe ecológica comparável ao buraco na camada de ozônio - não se desencadeiam gratuitamente.

É flagrante a concepção que permeia o manual didático Projeto Pitanguá: Ciências (2005) quando aborda a questão da Conservação do solo na unidade um. Em um texto extraído do livro $O$ solo e a vida (2001), de Rocicler Martins Rodrigues, produzido pela própria Editora Moderna, responsabiliza as pessoas, individualmente, pela solução dos problemas com o lixo, eximindo a reprodução destrutiva do capital de responsabilidade, nessa e em outras questões subjacentes, como podemos constatar na transcrição abaixo:

Mesmo enterrado o lixo continua poluindo, pois sua decomposição produz um líquido chamado chorume, que mata os seres vivos do solo e pode atingir a água dos poços e os lençóis subterrâneos. Portanto, as soluções para o problema do lixo são: redução de sua produção, recolhimento seletivo e reciclagem. / Quando economizamos energia elétrica, gasolina e o óleo diesel, também estamos contribuindo para a conservação do solo, pois essa economia pode evitar que mais usinas hidrelétricas sejam construídas e até mesmo desacelerar o processo de extração do petróleo. Com isso, o solo será poupado de inundações e escavações. Pode-se economizar, por exemplo, não deixando lâmpadas e aparelhos elétricos ligados sem necessidade e utilizando mais transporte coletivo. (EDITORA MODERNA, 2005, p. 15, grifo do autor).

Analisando essa transcrição, enfatizamos novamente que não é preocupação do capital o fato de que as usinas hidrelétricas destroem o solo, porque exatamente elas são construídas para atender às necessidades estruturais para a reprodução destrutiva do capital. Note-se também que nesse texto o manual didático perde a oportunidade de, a rigor, trazer essa discussão à tona.

Nos manuais didáticos em questão, o ambiente é tratado de forma abstrata e como se o homem não fosse parte da natureza. Como se os homens, por meio do trabalho, não transformassem esse ambiente descrito pelos livros. Em Ciências: o meio ambiente, capítulo 
5, Barros e Paulino (2006, p. 42-43) abordam "A distribuição da vida na biosfera" exemplo, o homem é citado apenas duas vezes. Uma ao informar o nome do autor da música Suite dos pescadores (Dorival Caymmi), como parte de uma atividade de perguntas e respostas, cuja letra é figurativa e isenta de qualquer relação com o que pedem as perguntas. Outra, em uma das atividades ao final do capítulo, em que solicitam aos alunos a identificação de "[...] três motivos que justificam a importância dos ambientes aquáticos de água salgada ou de água doce - para os interesses humanos [...]", sem que em momento algum essa questão tenha sido aventada (BARROS; PAULINO, 2006, p. 57, grifo nosso). São onze páginas com apenas duas referências à existência humana, sem estabelecer relação alguma entre homem/natureza e as condições de reprodução das espécies, entre elas o homem. Sob o ponto de vista dos autores, o homem nem mesmo é um dos "fatores" que influenciam "a distribuição da vida no ambiente", pois nem se quer é citado como tal, fazendo uma descrição mecânica dos conteúdos ali veiculados.

As soluções para os problemas ambientais sugeridas pelos manuais didáticos são paliativas e evasivas, uma vez que

A dificuldade não está apenas no fato de os perigos inseparáveis do atual processo de desenvolvimento serem hoje muito maiores do que em qualquer outro momento, mas também no fato de o sistema do capital global ter atingido o seu zênite contraditório de manutenção e saturação. Os perigos agora se estendem por todo o planeta; consequentemente, a urgência de soluções para eles, antes que seja tarde demais, é especialmente severa. Para agravar a situação, tudo se torna mais complicado pela inviabilidade de soluções parciais para o problema a ser enfrentado. Assim, nenhuma "questão única" pode, realisticamente, ser considerada a "única questão". (MÉSZÁROS, 2006, p. 95, grifo do autor).

Analisando a abordagem ambiental feita pelos manuais didáticos aqui apresentados, constatamos, que além de trazerem um conteúdo simplificado, vulgarizado e sonegado, as obras não levantam discussões sobre a totalidade da sociedade capitalista. Tratam os problemas ambientais como se fossem resultado de causas naturais, desprezam a ação do homem sobre a natureza, desconsideram a relação capital e trabalho como determinantes da relação homem/natureza, bem como a necessidade desse metabolismo para a reprodução do capital. O capital, antes de ser uma "entidade material", mas uma estrutura "totalizadora" que tudo controla, inclusive os homens, não é um mecanismo neutro. Nas palavras de Mészáros (2006, p. 96, grifo do autor):

[...] Não se pode imaginar um sistema de controle mais inexoravelmente absorvente - e, neste importante sentido, "totalitário" - do que o sistema do capital globalmente dominante, que sujeita cegamente aos mesmos imperativos a questão da saúde e a do comércio, a educação e a agricultura, a arte e a indústria manufatureira, que implacavelmente sobrepõe a tudo seus próprios critérios de viabilidade, desde as menores unidades de seu "microcosmo" até as mais gigantescas empresas transnacionais, desde as mais íntimas relações pessoais aos mais complexos processos de tomada de decisão dos vastos monopólios industriais, sempre a favor dos fortes e contra os fracos $[\ldots]$.

Diante do quadro esboçado até aqui, pudemos constatar que o professor contemporâneo, da mesma forma que o professor comeniano, tem os procedimentos didáticos e os conteúdos programáticos vulgarizados e ditados pelos manuais em sua prática 
escolar. O nível de desconhecimento do professor a respeito de seu trabalho chega a tal ponto, que permite aos autores argumentações do tipo: "Para evitar uma escolha arbitrária de questões [...]", subentendendo a incapacidade dos docentes de realizar as tarefas que lhes são devida (EDITORA MODERNA, 2006, p. 14). O manual didático é, portanto, de tal forma excludente que implica também no descompromisso do professor de pensar o trabalho didático.

\section{Considerações finais}

O tom catastrófico sobre os problemas ambientais ecoa nos manuais didáticos de forma "[...] grotescamente desfigurada e exagerada unilateralmente para que as pessoas suficientemente impressionadas com o tom [...] dos sermões ecológicos - possam ser, com sucesso, desviadas dos candentes problemas sociais e políticos [...]" (MÉSZÁROS, 2006, p. 987). Nessa esteira, o que se propõe às pessoas é a aceitação do sacrifício envolvendo a precarização de suas condições de vida para possibilitar a "recuperação do ambiente" e cobrir "[...] os custos necessários à manutenção do atual sistema de expansão da produção de supérfluos [...]", além de sustentar,

[...] sob o pretexto da 'sobrevivência da espécie humana', a sobrevivência de um sistema sócio-econômico [sic] que se defronta agora, com deficiências derivadas da crescente competição internacional e de uma mudança crescente, na própria estrutura de produção, em favor dos setores parasitários. (MÉSZÁROS, 2006, p. 987-988, grifo do autor).

Essa é a maneira como o capital age em relação às questões que envolvem a relação homem/natureza. Entretanto, não se pode negar que, mesmo utilizadas em benefício dos interesses da grande indústria, são questões reais, inerentes à expansão do capitalismo e que devem ser levadas a sério sob pena da supressão da própria existência humana no planeta.

O manual didático, como um dos instrumentos disseminadores do conhecimento construído pela humanidade e como instrumento ideológico que assegura as regras do jogo capitalista, apresenta, como vimos, limites à compreensão da contradição entre transformação da natureza para acumulação do capital e a transformação da natureza para obtenção dos meios de subsistência do homem como conjunto da sociedade, com vistas à superação do modo de produção capitalista.

A questão dos problemas ambientais enfrentados hoje pela humanidade, a partir da propriedade privada, está diretamente ligada ao processo de trabalho como ação do homem sobre a natureza para obtenção dos "meios de vida" pela transformação daquela. Ao apropriar-se conscientemente da natureza e pela própria vontade, o homem se distancia dela dominando-a, tornando-a sua "obra", objetivada pelo trabalho, confirmando-o como um "ser genérico". Sem a natureza o trabalhador não cria nem produz. O capital não admite restrições das pressões materiais envidadas pelos obstáculos que se apresentam, muito menos a urgência em enfrentá-los. Para o sistema do capital, apenas remeter-se à ideia de "restrição" já significa uma "crise".

Dessa forma, o que os manuais didáticos apresentam como conhecimento, nem sequer se aproxima do que podemos considerar como conhecimento acumulado historicamente como patrimônio do gênero humano. Esses conhecimentos propostos pelos manuais didáticos retiram do conteúdo as reais condições e possibilidades de enfrentamento dos problemas causados pelo avanço da produtividade no sistema capitalista. Não apontam as origens e os meandros da reprodução constantemente ampliada do capital como resultado 
das atuais e futuras condições de existência da humanidade.

O manual didático nem se quer abre espaço para a dúvida de seus pressupostos, que dirá para o debate aberto da luta de classes, evitando o contato direto com a realidade e focando nas disputas formais e verbais. Em um único exemplo: no manual didático, são ignoradas as implicações do agronegócio na contaminação desmedida do solo e como são as relações de exploração dos meios naturais e sociais para obtenção de lucros bilionários desse setor industrial, à custa da própria existência presente e futura da humanidade e do planeta. Essa condição se mantém viva no ambiente escolar, atendendo da mesma forma as exigências da sociedade atual, ou seja, a preparação profissional para o mundo do trabalho no modo de produção capitalista.

\section{REFERÊNCIAS}

ALVES, G. L. A produção da escola pública contemporânea. Campinas: Autores Associados, 2001.

ALVES, G. L. O trabalho didático na escola moderna. Campinas: Autores Associados, 2005 .

BARROS, C.; PAULINO, W. R. Ciências: meio ambiente - manual do professor. São Paulo: Ática, 2006. (Coleção Ciências).

BRASIL. Ministério da Educação. Secretaria de Educação Básica. Fundo Nacional de Desenvolvimento da Educação. Guia de livros didáticos: PNLD 2013: ciências. Brasília, DF: Ed. Ministério da Educação, 2012. Disponível em: <http://www.fnde.gov.br/arquivos/category/125-guias?download=7366:pnld-2013ciencias>. Acesso em: 10 jan. 2015.

BRASIL. Ministério de Educação. Ensino fundamental de nove anos: orientações para a inclusão da criança de seis anos de idade. Brasília, DF: Ed. Ministério de Educação, 2007. Disponível em:

<http://portal.mec.gov.br/seb/arquivos/pdf/Ensfund/ensifund9anobasefinal.pdf $>$. Acesso em: 10 jan. 2015.

BRASIL. Secretaria de Educação Fundamental. Parâmetros Curriculares Nacionais: Ciências Naturais. Brasília: MEC/SEF, 1998.

BRASIL. Presidência da República. Lei n. 11.274, de 6 de fevereiro de 2006 Altera a redação dos arts. 29, 30, 32 e 87 da Lei no 9.394, de 20 de dezembro de 1996, que estabelece as diretrizes e bases da educação nacional, dispondo sobre a duração de 9 (nove) anos para o ensino fundamental, com matrícula obrigatória a partir dos 6 (seis) anos de idade. Diário Oficial [da] República Federativa do Brasil, Brasília, DF, 7 fev. 2006. Disponível em: <http://www.planalto.gov.br/ccivil_03/_Ato20042006/2006/Lei/L11274.htm>. Acesso em: 2 jan. 2015.

CAMBI, F. História da pedagogia. São Paulo: Fundação Editora da UNESP (FEU), 1999. 
CAMPOS. R. B. Memórias de manuais de História. Em Aberto, Brasília, DF, v. 16, n. 69, p. 91-97, 1996. Disponível em:

<http://emaberto.inep.gov.br/index.php/emaberto/article/viewFile/1041/943>. Acesso em: 10 jan. 2015.

CHESNAIS, F.; SERFATI, C. "Ecologia" e condições físicas da reprodução social: alguns fios condutores marxista. Crítica Marxista, Campinas, n. 16, p. 39-75, 2003.

CHOPPIN, A. História dos livros e das edições didáticas: sobre o estado da arte.

Educação e Pesquisa, São Paulo, v. 30, n. 3, p. 549-566, 2004. Disponível em:

<http://www.revistas.usp.br/ep/article/download/27957/29729>. Acesso em: 10 jan. 2015.

COMENIUS, I. A. Didática magna. 3. ed. São Paulo: Martins Fontes, 2006. Trabalho original publicado em 1621-1657.

EDITORA MODERNA. (Org.). Projeto Araribá: Ciências. São Paulo: Moderna, 2006.

Obra coletiva, concebida e desenvolvida pela Editora Moderna.

EDITORA MODERNA. (Org.). Projeto Pitanguá: Ciências. São Paulo: Moderna, 2005.

Obra coletiva, concebida e desenvolvida pela Editora Moderna.

FERNANDES, A. T. C. Livros didáticos em dimensões materiais e simbólicas. Educação e Pesquisa, São Paulo, v. 30, n. 3, p. 531-545, 2004. Disponível em:

<http://www.revistas.usp.br/ep/article/download/27956/29728>. Acesso em: 23/06/2008.

FOLADORI, G. Limites do desenvolvimento sustentável. Campinas: Ed. Unicamp, 2001.

FRACALANZA, H. O que sabemos sobre o livro didático para o ensino de Ciências no Brasil. 1992. 304 f. Tese (Doutorado em Educação) - Universidade Estadual de

Campinas, Campinas, 1992. Disponível em:

<http://www.bibliotecadigital.unicamp.br/document/?down=vtls000057868>. Acesso em: 10 jan. 2015.

GALEANO, E. Somos todos culpados pela ruína do planeta. Portal vermelho, jul. 2007. Disponível em: http://www.vermelho.org.br/noticia.php?id_noticia=20917\&id_secao=9. Acesso em: 04/06/2010.

GATTI JÚNIOR, D. A escrita escolar da história: livro didático e ensino no Brasil (19701999). Bauru: Edusc, 2004.

GATTI JÚNIOR, D. Estado e editoras privadas no Brasil: o papel e o perfil dos editores de livros didáticos. Cadernos CEDES, Campinas, v. 25, n. 67, p. 365-377, 2005.

Disponível em: <http://www.scielo.br/pdf/ccedes/v25n67/a08v2567.pdf>. Acesso em: 10 jan. 2015.

KONDER, L. Marxismo e alienação: contribuição para um estudo do conceito marxista de alienação. 2. ed. São Paulo: Expressão Popular, 2009.

LESSA, S.; TONET, I. Introdução à filosofia de Marx. 1. ed. São Paulo: Expressão Popular, 2008. 
MARX, K. Livro I - o processo de produção do capital. In: MARX, K. O capital: crítica da economia política. São Paulo: Nova Cultural, 1985a. v. 1. Trabalho original publicado em 1867.

MARX, K. Livro I - o processo de produção do capital. In: MARX, K. O capital: crítica da economia política. São Paulo: Nova Cultural, 1985b. v. 2. Trabalho original publicado em 1867.

MARX, K.; ENGELS, F. A ideologia alemã: crítica da mais recente filosofia alemã em seus representantes Feuerbach, B. Bauer e Stirner, e do socialismo alemão em seus diferentes profetas. São Paulo: Boitempo, 2007. Trabalho original publicado em 1932.

MARX, K.; ENGELS, F. Manifesto do partido comunista. 3. ed. Petrópolis: Vozes, 1990. Trabalho original publicado em 1848.

MEGID NETO, J.; FRACALANZA, H. O livro didático de ciências: problemas e soluções. Ciência \& Educação (Bauru), Bauru, v. 9, n. 2, p. 147-157, 2003. Disponível em: 〈http://www.scielo.br/pdf/ciedu/v9n2/01.pdf>. Acesso em: 10 jan. 2008.

MENTALIDADE. In: HOUAISS, A.; VILLAR, M. S. Dicionário Houaiss de língua portuguesa. Rio de Janeiro: Objetiva, 2009. Não paginado. CD-ROM.

MÉSZÁROS, I. Educação para além do capital. São Paulo: Boitempo, 2005.

MÉSZÁROS, I. Para além do capital: rumo a uma teoria da transição. São Paulo: Boitempo, 2006

MÉSZÁROS, I. Produção destrutiva e Estado capitalista. São Paulo: Ensaio, 1989.

MUNAKATA, K. Produzindo livros didáticos e paradidáticos. 1997. 218 f. Tese (Doutorado em História e Filosofia da Educação) - Pontifícia Universidade Católica de São Paulo, São Paulo, 1997. Disponível em:

<http://www.academia.edu/3763517/Produzindo_livros_did\%C3\%A1ticos_e_paradid\%C3 \%A1ticos>. Acesso em: 10 jan. 2015.

NETTO, J. P.; BRAZ, M. Economia política: uma introdução crítica. 8. ed. São Paulo: Cortez, 2012.

OLIVEIRA, A. L. O livro didático. Rio de Janeiro: Tempo Brasileiro, 1968.

SIMPÓSIO INTERNACIONAL - LIVRO DIDÁTICO: EDUCAÇÃO E HISTÓRIA, 1., 2007, São Paulo. Anais... São Paulo: Faculdade de Educação da Universidade de São Paulo, 2007. 1 CD-ROM.

SOUZA, A. M. C. Obediência ou transgressão? Eis a questão! A crença de professores de língua inglesa de cursos livres sobre a utilização do livro didático. $2007.118 \mathrm{f}$.

Dissertação (Mestrado em Lingüistica Aplicada) - Universidade de Brasília, Brasília, DF, 2007. Disponível em:

<http://bdtd.bce.unb.br/tedesimplificado/tde_busca/arquivo.php?codArquivo=2749>.

Acesso em: 10 jan. 2015. 
TONET, I. Educação contra o capital. 2. ed. rev. São Paulo: Instituto Lukács, 2012.

TONET, I. Educação e ontologia marxiana. Revista HISTEDBR On-line, Campinas, p. 135-145, 2011. Número especial. Disponível em:

<http://www.histedbr.fe.unicamp.br/revista/edicoes/41e/art10_41e.pdf >. Acesso em: 10 jan. 2015

TONET, I. Um novo horizonte para a educação. Palestra proferida no I Congresso de Ontologia do Ser Social e Educação, São José do Rio Preto, 2007. Disponível em: <http://ivotonet.xpg.uol.com.br/arquivos/UM_NOVO_HORIZONTE_PARA_A_EDUCA CAO.pdf>. Acesso em: 10 jan. 2015.

ZILBERMAN, R. No começo, a leitura. Em Aberto, Brasília, v. 16, n. 69, p. 16-29, 1996. Disponível em:

<http://emaberto.inep.gov.br/index.php/emaberto/article/viewFile/1035/937>. Acesso em: 10 jan. 2015.

\section{Notas}

\footnotetext{
${ }^{1}$ Este artigo é fruto de pesquisa concluída no curso de mestrado realizado no Programa de Pós-Graduação em Educação da Universidade Federal de Mato Grosso do Sul. Salientamos que o texto aqui apresentado é um recorte que aborda sinteticamente a análise específica dos manuais didáticos selecionados para esta investigação. Observando que algumas referências bibliográficas foram atualizadas.
}

${ }^{2}$ Professora Mestre do curso de Educação Física no Campus do Pantanal/Universidade Federal de Mato Grosso do Sul e doutoranda do Programa de Pós-Graduação em Educação da Universidade Federal de Mato Grosso do Sul.

${ }^{3}$ Simpósio Internacional - Livro Didático: Educação e História (2007), com 154 trabalhos apresentados; Fernandes (2004) trata do manual didático com enfoque na sua função de transmissão dos conhecimentos; Oliveira (1968) e Choppin (2004), em relação ao manual didático, analisam como este se constituiu historicamente; Zilberman (1996) e Souza (2007) investigam o manual didático como estruturador da atividade de ensino; Fracalanza (1992) e Megid Neto e Fracalanza (2003) falam sobre melhoria de qualidade; Campos (1996) apresenta a respeito da ideologia veiculada pelo manual didático.

${ }^{4}$ Gilberto Luis Alves é o autor que dá início ao debate sobre o tema e faz a crítica contundente ao "livro didático", afirmando sua eliminação/supressão como mediador da relação educativa. Nas obras A produção da escola pública contemporânea (2001) e O trabalho didático na escola moderna (2005) ele propõe uma discussão sobre os caminhos da "organização do trabalho didático" (categoria rubricada por esse autor) no interior das instituições educacionais, vinculado à organização técnica do trabalho.

${ }^{5}$ Bispo e educador Jan Amos Comenius (1592-1670), nasceu em Nivnice, Moravia, hoje República Tcheca, um dos expoentes intelectuais do período manufatureiro.

${ }^{6}$ Segundo Netto e Braz (2007, p. 55), “A práxis envolve o trabalho, que, na verdade, é o seu modelo [...] devese distinguir entre formas de práxis voltadas para o controle e a exploração da natureza e formas voltadas para influir no comportamento e na ação dos homens [...]". Aqui trata-se da relação entre os indivíduos que atuam sobre si mesmos - a práxis educativa.

${ }^{7} \mathrm{O}$ que caracteriza significativamente o trabalho do educador morávio é a síntese mais elevada do trabalho educativo, juntamente com o nascimento do mundo moderno. 
${ }^{8}$ Por um compromisso de sigilo de pesquisa sobre a identidade das escolas, estas serão identificadas por escola A e escola B.

${ }^{9}$ Sem aprofundarmos o tema, por não ser o documento citado objeto de nossas investigações, abrimos aqui um parêntese porque não poderíamos deixar de chamar a atenção para o tratamento dado pelo Estado à educação, como uma das dimensões da sociedade. Ao ignorar as reais condições de ensino no Brasil, o documento deixa passar ao largo o debate sobre o que, concretamente, impede a formação de indivíduos conscientes de sua condição de homens em uma sociedade capitalista, ocultando a luta de classes, ao usar a expressão "setores populares" e sugerindo, nas entrelinhas, que a simples reforma na seriação do ensino seja solução para os problemas enfrentados pela educação no país.

${ }^{10}$ Trazemos aqui uma síntese dos objetivos encontrados nos três manuais analisados: identificar os elementos do ambiente, percebendo-os como parte de processos de relações, interações e transformações; perceber a profunda interdependência entre os seres vivos e os demais elementos do ambiente; contribuir com a melhoria da qualidade do ensino; compreender a tecnologia como recurso para resolver as necessidades humanas, diferenciando os usos corretos e úteis daqueles prejudiciais ao equilíbrio da natureza e ao ser humano; pautar as questões ambientais em princípios claros, compartilhados pelos membros da comunidade educativa, que guiam as ações para atingir os melhores resultados, entre outros.

${ }^{11}$ Tipo de relação entre as espécies, que assim é explicado no livro: "Quando seres de uma espécie capturam e destroem fisicamente seres de outra espécie, utilizando-os como alimento [...]” (BARROS; PAULINO, 2006, p. 40).

${ }^{12}$ Para Barros e Paulino (2006, p. 46, grifo nosso), “A biosfera compreende o conjunto de todos os ecossistemas da Terra. Portanto, é a porção do planeta onde a vida se instala." Isso deveria significar a participação do homem (o que não ocorre), também, como porção da vida, uma vez que está em absoluta relação com a natureza, pois é por meio dessa relação que a sua existência se realiza.

Recebido: fevereiro-15 $\quad$ Aprovado: $\quad$ março-15 